Public Health
Genomics
Public Health Genomics 2010;13:116-124

DOI: $\underline{10.1159 / 000226595}$
Received: August 7, 2008

Accepted after revision: April 16, 2009

Published online: June 29, 2009

\title{
What Can Interest Tell Us about Uptake of Genetic Testing? Intention and Behavior amongst Smokers Related to Patients with Lung Cancer
}

\author{
S.C. Sanderson ${ }^{a} \quad$ S.C. O'Neill ${ }^{b} \quad$ L.A. Bastian ${ }^{c, d} \quad$ G. Bepler $\quad$ C.M. McBride \\ ${ }^{a}$ Department of Genetics and Genomic Sciences, Mount Sinai School of Medicine, New York, N.Y., ${ }^{b}$ Cancer Control \\ Program, Lombardi Cancer Center, Georgetown University, Washington, D.C., ' General Internal Medicine, Duke \\ University Medical Center, and d Center for Health Services Research in Primary Care, Durham, N.C., ${ }^{e}$ H. Lee Moffitt

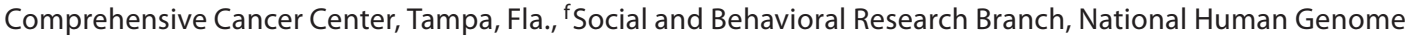 \\ Research Institute, National Institutes of Health, Bethesda, Md., USA
}

\section{Key Words}

Attitudes · Complex diseases • Decision-making •

Evaluation of genetic/genomic tools for public health •

Genetic testing $\cdot$ Interest $\cdot$ Lung cancer $\cdot$ Uptake

\begin{abstract}
Background: Much of the research examining psychosocial aspects of genetic testing has used hypothetical scenarios, based on the largely untested assumption that hypothetical genetic testing intentions are good proxies for behavior. We tested whether hypothetical interest predicts uptake of genetic testing and whether factors that predict interest also predict uptake. Methods: Participants $(n=116)$ were smokers and related to patients with lung cancer, who completed a telephone survey. Interest in genetic testing for lung cancer risk was indicated by responding 'definitely would' to a Likert-style question. Internet-delivered genetic testing for lung cancer risk was then offered. Uptake was indicated by requesting the test and receiving the result. Results: $63 \%$ of participants said they 'definitely would' take the genetic test; uptake was $38 \%$. Participants who said they 'definitely would' take the test were more likely than others to take the offered test ( $45 \%$ vs. $26 \%, p=0.035$ ). Interest was associated with attitudes towards genetic testing and motivation to quit smoking. Uptake was associated with motivation, prior
\end{abstract}

\section{KARGER}

Fax +4161306 1234

E-Mail karger@karger.ch

www.karger.com
(C) 2009 S. Karger AG, Basel

$1662-4246 / 10 / 0132-0116 \$ 26.00 / 0$

Accessible online at:

www.karger.com/phg awareness of genetic testing, and daily Internet use. Conclusion: Hypothetical interest only modestly predicts uptake of genetic testing. Interest in genetic testing likely reflects generally positive attitudes that are not good predictors of the choices individuals subsequently make.

Copyright $\odot 2009$ S. Karger AG, Basel

Genetic susceptibility tests for common gene variants associated with common health conditions such as lung cancer, heart disease, and diabetes are proliferating commercially (www.23andme.com, www.navigenics.com, www.decodeme.com) and are predicted to be used clinically in the future $[1,2]$. Assessing interest in genetic testing for these conditions using hypothetical testing scenarios (or vignettes) is potentially useful because it may provide information on potential demand for genetic testing services and characteristics of those who seek such testing, which can in turn shed light on information needs of consumers and patients and inform public policy debate [3].

Given current reluctance in some quarters to conduct research that offers genetic testing and feedback to individuals for common gene variants, it is likely that hypothetical interest will continue to be assessed and the hypothetical vignette design to be used as an informative 
methodological tool for the foreseeable future. However, this rests on the assumption that people's stated intentions when posed with hypothetical genetic testing scenarios are a good proxy for their behavior. In fact, it is well documented from other areas of behavioral research such as condom use, screening, diet, and exercise that there is an intention-behavior gap [4]. However, despite this gap, intention remains the key cognition, accounting for about $28 \%$ of the variance in behavior [4].

Little is known about the association of hypothetical interest with uptake of genetic testing for common health conditions. Although the limited evidence available suggests that hypothetical interest generally overestimates actual uptake of genetic testing [5], few studies have tested associations of hypothetical interest with test uptake within a single sample to evaluate whether there really is a gap between what people say they will do and what they actually do with respect to genetic testing [5]. In a recent systematic review [5] 25 papers were identified that examined genetic testing intentions for breast cancer, but only 1 of these also examined actual uptake of genetic testing [6]. In that study $55 \%$ of participants stated that they intended to undergo genetic testing, and this was consistent with their behavior: $52 \%$ subsequently gave blood for genetic testing [6]. Persky and colleagues [7] identified 38 studies examining interest in genetic testing of which half focused on interest in genetic testing for breast/ovarian cancer and the other half examined interest in genetic testing for prostate cancer, colon cancer, lung cancer, non-specific cancer (i.e., the type of cancer was not specified to participants), Alzheimer's disease, or heart disease. Only one study was identified which assessed interest in genetic testing for lung cancer, finding an interest level of $60 \%$ [8].

Much of the work on psychosocial aspects of genetic testing has been in the area of monogenic disorders such as familial cancer syndromes and Huntington's disease. In the case of Huntington's disease hypothetical interest and test uptake have been highly incongruent, with interest tending to be high at around $70-80 \%$ and uptake tending to be low at $10-20 \%$ [9]. This incongruence may be explained by the catastrophic and debilitating nature of this monogenic disease. Being faced with the almost certain reality of learning one is destined for the outcome may be more appealing in the hypothetical but far more difficult when faced with the real opportunity to know. Genetic susceptibility tests for common health conditions with multiple causes and polygenic modes of inheritance are becoming available; these tests will be associated with modest increases in disease risk. Using hy- pothetical vignettes in these circumstances may yield intentions that are more closely aligned with actual behavior as the information provided is likely to be less emotionally charged than predictive genetic testing for monogenic diseases.

In addition to examining absolute levels of interest and uptake, there has been considerable research effort to identify demographic and cognitive characteristics of people who do and do not take genetic tests. This helps to identify information needs of different population subgroups and provides important information about equity of access to this new technology and what may be the potential needs of those who seek testing. However, again it is not clear whether the same factors that predict interest also predict uptake and how useful it is to identify the former is unclear.

Both hypothetical interest and actual uptake were assessed in the Family Risk and Lung Cancer Study, a study in which smokers related to patients with lung cancer were offered genetic testing [10]. The aim of the present analyses was to test the assumptions implicit in studies of hypothetical interest, namely, that hypothetical interest in genetic testing is a good surrogate for actual uptake of genetic testing. On this basis, we made the following 2 hypotheses: (1) interest in genetic testing for lung cancer risk will predict actual uptake of genetic testing for lung cancer risk and (2) the same factors that predict interest will predict actual uptake of genetic testing for lung cancer risk.

\section{Methods}

\section{Recruitment and Procedure}

Participants were recruited for this study in tandem with a larger multi-site smoking cessation trial. Patients with stage IIIB/ IV lung cancer, who were receiving care in the Thoracic Oncology Clinic at the H. Lee Moffitt Cancer Center and Research Institute in Tampa, Florida, were identified through their providers. The patients were approached by a recruiter during their clinic visit and asked if they would be willing to be contacted for a brief telephone survey. The 482 patients who agreed signed a consent form indicating that they were willing to have their personal health information forwarded to the survey center at Duke University, North Carolina.

Within 1 week, a trained interviewer called the patient to complete the survey. The survey was completed by 391 patients or their proxies. As part of the survey, patients were asked to give the names, addresses, and telephone numbers of all the smokers in their family and asked for permission to contact these 'relativesmokers'. The 539 relative-smokers who were identified were sent a letter informing them about the study and given a toll-free number to call if they did not want to participate. Those who did not call the number $(n=530)$ were called by interviewers from Bat- 


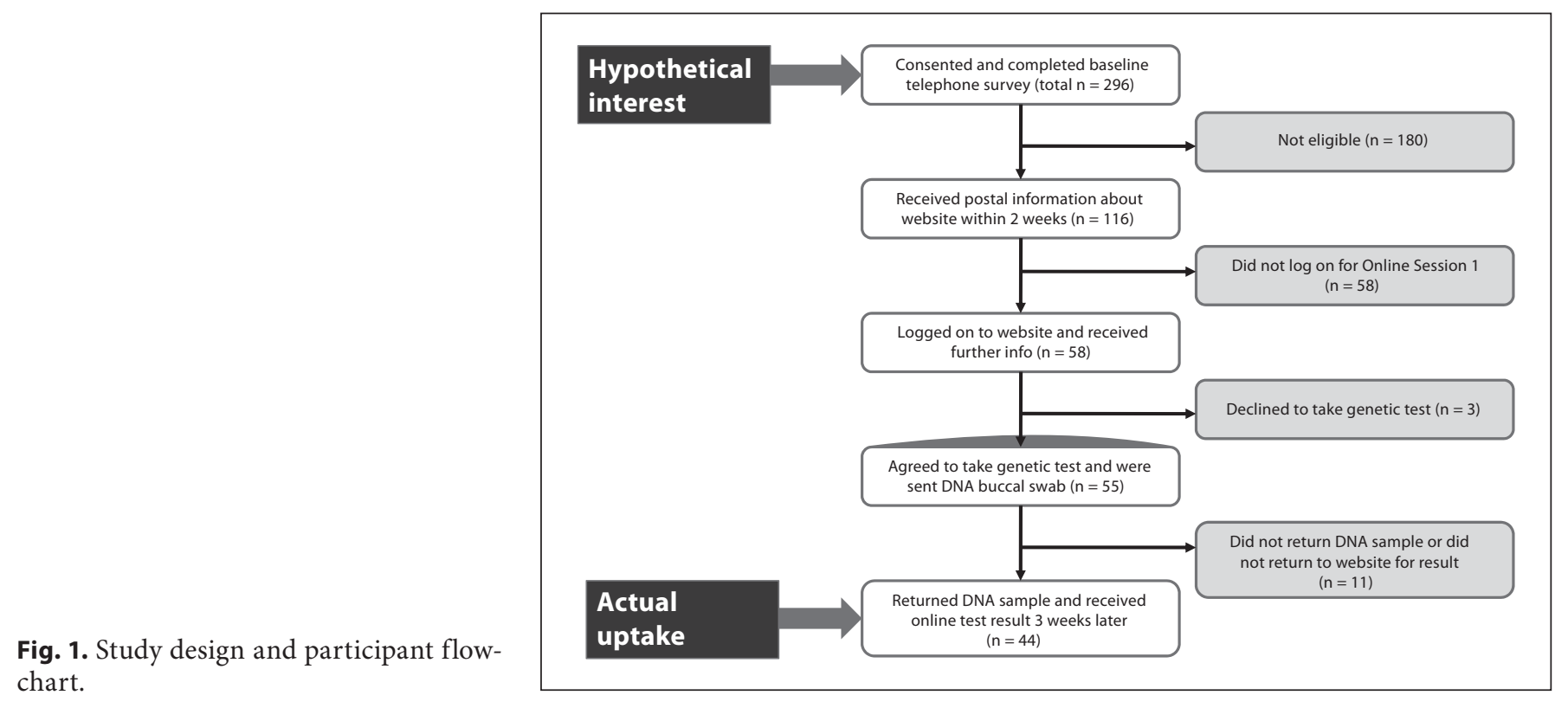

telle Survey Research Associates. Those who were successfully contacted $(n=365)$ were asked to complete a 30-minute telephone survey. Three hundred and four relative-smokers completed the interview, of whom 8 refused to participate further, thus leaving an initial sample size of 296 relative-smokers.

Relative-smokers were eligible to participate in the present study if they: (1) were a biological first- or second-degree relative of the patient, (2) were aged 18 to 55 years, (3) had smoked at least 7 cigarettes in the prior week and at least 100 in their lifetime, (4) had not had cancer themselves, (5) had access to the Internet, (6) spoke English, and (7) scored less than 14 on the Centers for Epidemiological Survey of Depression Scale. These criteria were set to increase the salience of the test context whilst minimizing psychological risks of the low intensity communication format. As shown in figure 1, based on these inclusion criteria 180 individuals were ineligible for participation in the present study. Participants who were deemed ineligible completed the telephone survey but were not invited to proceed any further with the present study. This did not affect their eligibility for participation in the larger multi-site smoking cessation trial.

Eligible relative-smokers were asked whether they would be willing to participate in a study about the beliefs and attitudes of relatives of patients with lung cancer towards lung cancer risk, genetics, and genetic testing and how these might influence their desire to quit smoking. They were informed that participation would involve reviewing web-based information and that genetic testing and smoking cessation materials would be offered free of charge. Multiple members of the family could participate; 116 relative-smokers from 95 unique families agreed to participate in the study. Within 2 weeks, relative-smokers who had given their informed consent received a packet of information including a user ID and password and were invited to log on to session 1 of the website. A total of 58 relative-smokers logged on to the website.

Relative-smokers who visited the website were guided through a series of structured steps, including an overview of study proce- dures and additional consenting information. As part of this session 1 , they completed a brief survey and were then guided through a series of 21 consecutive information pages about the roles of smoking and genetics in the development of lung cancer. The development and structure of the web content was guided by theoretical models [11-14], clinical models of genetic services delivery, and the notion that the relative-smokers may be experiencing a 'teachable moment' given their relatives' diagnosis of lung cancer [15]. Topics covered included: How does lung cancer develop? What is harmful about cigarette smoke? How can you lower your risk of lung cancer? Pros to consider in deciding about genetic testing (strengths of the GSTM1 test); Cons to consider in deciding about genetic testing (weaknesses of the GSTM1 test). The strengths list included: the result gives you information about one of the ways your body may handle the chemicals in cigarette smoke that cause lung cancer; the results could motivate you to quit smoking; the test is simple and painless. The weaknesses listed included: if you are found to be at higher genetic risk, the news could be distressing; the result may not motivate you to quit smoking; the result can only tell you whether your risk is higher or lower than average, not whether or not you will get lung cancer; the result will not tell you about your genetic risk for other diseases of smoking. The information pages also included the information that smokers who have the GSTM1 enzyme may be at slightly lower risk of getting lung cancer, and that smokers who do not have the GSTM1 enzyme may be at slightly higher risk of getting lung cancer.

Relative-smokers could move backwards and forwards within the presentation of the information. After reviewing the information, the relative-smokers began a survey section and were not able to move back into the information section. At this point, they were offered free genetic testing for the GSTM1 genotype. They were given the options to accept, decline, or delay the decision to take the test. Those who agreed to be tested for GSTM1 were sent a buccal swab kit, instructions for collecting the sample, a consent form, and a postage-paid return mailing. 
Buccal samples were processed within 2 weeks of collection by a Clinical Laboratory Improvement Act-approved lab at Duke University. The DNA samples were not stored for future use.

After about 3 weeks, participants who had completed the online session 1 were emailed and asked to return to the website for session 2 and to receive their results or to review smoking cessation materials. Of the 58 relative-smokers who logged on to session 1, 55 agreed to take the test and were sent the buccal swab and 3 declined to take the genetic test. Of the 55 who were sent the buccal swab, 11 did not return the DNA sample or did not return to the website for their result whilst 44 returned to the website for session 2 and received their genetic test result. Participants received \$50 each for completing measures at sessions 1 and 2 . They received this money regardless of whether or not they took the genetic test. Procedures were approved by the NHGRI and the Moffitt and Duke Institutional Review Boards.

\section{Measures}

All measures included in the present analyses, apart from 'actual uptake of genetic testing', were assessed in the baseline telephone survey.

\section{Hypothetical Interest in Genetic Testing}

Hypothetical interest was assessed with the following item: 'If a free blood test were available that could tell you whether you had a gene that gave you a higher than average chance of getting lung cancer, which of the following describes whether you would want to be tested in the next 6 months?' Response options were definitely not/probably not/possibly/probably/definitely would.

\section{Actual Uptake of Genetic Testing}

Actual uptake was indicated by the participants returning their DNA sample and obtaining their Internet-delivered personal GSTM1 genetic test result in the online session 2, i.e., these individuals were classified as having taken the genetic test. Participants who were sent a DNA buccal swab but did not return it or who returned their DNA sample but did not return to the website to receive their test result were categorized as not having taken the genetic test.

\section{Socio-Demographics}

Gender, age, education, and employment were assessed with standard measures. Frequency of Internet access was assessed with the item: 'How often do you access the Internet?' ( 1 = daily, 2 = weekly, 3 = monthly, $4=$ never). Participants who responded 'never' were excluded from the study.

\section{Awareness and Cognitions}

'Prior awareness of genetic tests for cancer risk' was assessed with a single item: 'Before today, have you ever heard about genetic tests for cancer risks?' ( $1=$ yes, $2=$ no).

'Perceived risk of lung cancer' was assessed with a single item: 'What do you think your risk of getting lung cancer is if you continue to smoke at your present level?' (1 = certain not to happen; 7 = certain to happen).

'Worry about lung cancer' was assessed with the item: 'How worried are you about getting lung cancer in your lifetime?' (1 = not at all worried; 5 = very worried).

'Positive attitudes towards genetic testing' were measured with the mean of 3 items (response options: strongly disagree, somewhat disagree, neutral, somewhat agree, strongly agree): 'You believe that being tested would help you get motivated to do things like quit smoking', 'You just want to know', and 'If you were at greater risk, you could make changes to lower your risk'. The items all loaded on to a single factor in factor analysis with communalities greater than 0.40 . The alpha coefficient was 0.70 .

'Negative attitudes towards genetic testing' were measured with the mean of 5 items (also with 5 response options from strongly disagree to strongly agree): 'You would be too worried that you might carry a gene that would increase your chance of getting lung cancer', 'You are afraid you would be too upset if you had the gene that increased your chance of lung cancer', 'If you found out you had a gene that increased your chance of lung cancer you would feel singled out', 'You are not sure the test would be accurate', and 'It's hard to believe that finding out your genetic test result would have any benefit to you' (items loaded on to a single factor with communalities greater than 0.4 , alpha coefficient $=$ $0.71)$.

\section{Smoking Characteristics}

'Motivation to quit smoking' was assessed with a single item, asking participants how much they wanted to quit smoking in the next 6 months on a scale from $1=$ not at all to $7=$ very much.

'Nicotine addiction' was assessed by asking participants how many cigarettes they smoked in a typical day and how long after waking they waited to smoke their first cigarette.

\section{Statistical Analyses}

Absolute levels of interest and uptake were examined with simple frequencies. A $\chi^{2}$ test was used to examine the association between interest and uptake. Unadjusted ANOVAs and $\chi^{2}$ tests were conducted to examine the bivariate associations between the predictor variables (socio-demographics, awareness and cognitions, and smoking characteristics) and the first dependent variable, hypothetical interest. Variables that were found to be significantly associated with hypothetical interest in the bivariate analyses were then entered simultaneously into a binary logistic regression to determine the independent associations between each of the variables and interest when adjusted for the other variables. Multiple smokers from the same family participated which led to intercorrelated data: we therefore accounted for aggregation of data by family membership by conducting the multiple logistic regression in a 2-level generalized linear mixed modeling framework. The models included a random intercept term for families, with individual respondents at level -1 and nested in families at level -2 . The bivariate and multivariate analyses were then repeated with uptake as the dependent outcome variable.

\section{Results}

\section{Level of Interest in Genetic Testing for Lung Cancer \\ Risk}

The majority of smokers eligible for being offered genetic testing $(n=116)$ reported that they would take a genetic test for lung cancer risk if it were offered to them: $73(63 \%)$ said that they 'definitely would' take the test, 22 
(19\%) said 'probably', and 18 (16\%) said 'possibly'. Only 1 (1\%) said 'probably not', and only 2 (2\%) said 'definitely not'.

We have previously reported that eligible smokers were more likely to be employed, smoked fewer cigarettes, and expressed fewer negative attitudes towards genetic testing for lung cancer risk than ineligible smokers [10]. We therefore also compared the level of interest in the full initial sample $(n=296)$ with the 116 eligible smokers in order to see whether interest levels were biased in this selected subgroup. We found that the proportion interested was similar in the full initial sample and the 116 eligible smokers $(66 \%$ of the full sample said they 'definitely would' take the test versus $63 \%$ in the subgroup). We also conducted a Mann-Whitney test and found that mean interest did not differ between eligible and ineligible smokers ( $4.41 \pm 0.90$ vs. $4.33 \pm 1.11, \mathrm{Z}=-0.26, \mathrm{p}=0.80)$. All further analyses were conducted only on the subgroup of eligible smokers.

\section{Relationship between Interest and Uptake}

As noted above, $63 \%$ of the 116 smokers in the present analyses said that they 'definitely would' take a genetic test for lung cancer risk if it were offered to them: yet only $38 \%$ subsequently took the test. Table 1 shows the proportions of smokers who took the test by their initial interest levels; uptake rates were $33 \%, 25 \%$, and $45 \%$, respectively, for smokers who responded that they 'definitely would not/probably would not', 'possibly/probably would', or 'definitely would' take the genetic test.

Because of the very small numbers of participants who responded 'definitely not' or 'probably not' $(\mathrm{n}=3)$, hypothetical interest was dichotomized into 'definitely would' versus other ('probably', 'possibly', 'probably not', and 'definitely not' combined) for the subsequent $\chi^{2}$ tests and binary logistic regressions (the latter of which additionally requiring a dichotomous rather than a categorical outcome). Smokers who had said that they 'definitely would' take a genetic test for lung cancer were significantly more likely than others to subsequently take the genetic test ( $45 \%$ vs. $26 \%, \chi^{2}=4.43, p=0.035$ ), indicating a modest but significant relationship between interest and uptake.

Among those who had said they 'definitely would' take the test, those who had daily Internet access were significantly more likely to act in accordance with their intentions and take the test: $54 \%$ of those with daily Internet access took the test compared to $24 \%$ of those with less than daily access $\left(\chi^{2}=5.45, \mathrm{p}=0.020\right)$.

Public Health Genomics 2010;13:116-124
Table 1. Hypothetical interest in and actual uptake of genetic testing for lung cancer risk

\begin{tabular}{lllll}
\hline Uptake & \multicolumn{2}{l}{ Interest, n (\%) } & $\begin{array}{l}\text { Total, } \\
\mathrm{n}(\%)\end{array}$ \\
\cline { 2 - 4 } & $\begin{array}{l}\text { definitely not/ } \\
\text { probably not }\end{array}$ & $\begin{array}{l}\text { possibly/ } \\
\text { probably }\end{array}$ & $\begin{array}{l}\text { definitely } \\
\text { would }\end{array}$ & \\
\hline No & $2(66)$ & $30(75)$ & $40(55)$ & $72(62)$ \\
Yes & $1(33)$ & $10(25)$ & $33(45)$ & $44(38)$ \\
Total & $3(3)$ & $40(34)$ & $73(63)$ & $116(100)$ \\
\hline
\end{tabular}

\section{Characteristics Associated with Interest}

In bivariate analyses, smokers who said that they 'definitely would' take a genetic test for lung cancer risk reported greater perceived risk of lung cancer $(p=0.007)$, greater worry about lung cancer $(\mathrm{p}=0.02)$, more positive attitudes towards genetic testing for lung cancer risk $(\mathrm{p}<$ 0.001 ), less negative attitudes towards genetic testing for lung cancer risk $(\mathrm{p}<0.001)$, and greater motivation to quit smoking $(\mathrm{p}<0.001)$ than smokers who did not say that they would definitely take the test (table 2). When entered into a binary logistic regression, positive attitudes and motivation to quit smoking remained positively associated with interest, negative attitudes remained negatively associated with interest, and perceived risk and worry were no longer significantly associated with interest (table 3).

\section{Characteristics Associated with Uptake}

In bivariate analyses, smokers who took the genetic test were more likely to be aged $34-45$ years $(p=0.036)$, were more likely to have daily access to the Internet $(\mathrm{p}=$ 0.013 ), were more likely to have previously heard of genetic tests for cancer risk ( $\mathrm{p}=0.039)$, and were more motivated to quit smoking $(\mathrm{p}=0.027)$ than smokers who did not take the genetic test (table 4). All variables except age (entered as a continuous variable) remained significantly predictive of uptake when entered into a binary logistic regression (table 5).

\section{Discussion}

We found that people who reported that they would definitely take a hypothetical genetic test if it were available to them were significantly more likely to subsequently take the test when it was offered than those who did not express definite interest ( $45 \%$ vs. $26 \%$ ). However, this as- 
Table 2. Associations between personal characteristics and interest in genetic testing for lung cancer risk in bivariate analyses $(\mathrm{n}=116)$

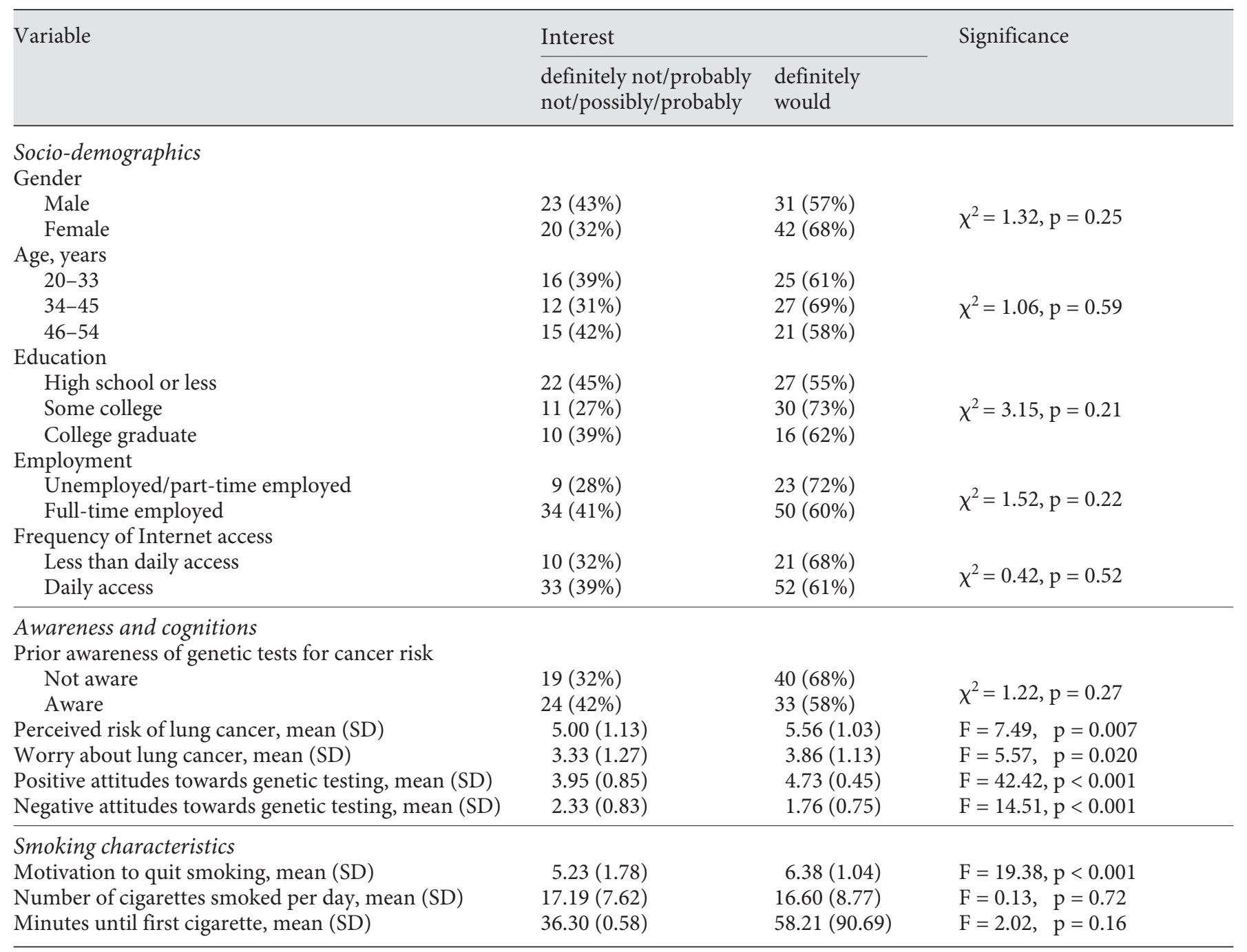

sociation between interest and uptake, although significant, was modest. It should be noted that $55 \%$ of people who had said that they definitely would take the test subsequently did not take the test. Thus, reported interest in testing is not a proxy for uptake. This finding is consistent with previous research from other health fields, such as screening, which have similarly found an intentionbehavior gap [4].

Interest in genetic testing for lung cancer risk in this study was generally high, with $63 \%$ of the smokers in this study saying they definitely would take such a test. This is consistent with the high levels reported in many other studies of genetic testing for a range of common conditions, including $60 \%$ for lung cancer [8], as well as $20-$ 96\% (mean 66\%) for breast cancer [5], 74-98\% for pros- tate cancer [16-22], and $69-80 \%$ for heart disease [23, 24].

We found that motivation to quit smoking predicted both interest in and uptake of genetic testing for lung cancer risk. We have previously reported that motivation to quit smoking was associated with logging on to the study website in the present sample [10]. The finding that motivation to quit smoking was the only factor to consistently predict both intention and behavior provides further evidence that smokers may opt to take genetic tests for smoking-related diseases because they hope to use some aspect of the procedure, information, and/or test results as a motivational tool to help them quit smoking [25]. 
Table 3. Independent associations between personal characteristics and hypothetical interest in genetic testing for lung cancer risk in multivariate logistical regression analysis

\begin{tabular}{|c|c|c|}
\hline \multirow[t]{2}{*}{ Variable } & \multicolumn{2}{|c|}{ Hypothetical interest } \\
\hline & $\exp b(95 \% \mathrm{CI})$ & $\mathrm{p}$ value \\
\hline Perceived risk of lung cancer & $1.38(0.80-2.38)$ & 0.24 \\
\hline Worry about lung cancer & $0.72(0.41-1.28)$ & 0.27 \\
\hline $\begin{array}{l}\text { Positive attitudes towards } \\
\text { genetic testing }\end{array}$ & $4.29(1.77-10.45)$ & 0.001 \\
\hline $\begin{array}{l}\text { Negative attitudes towards } \\
\text { genetic testing }\end{array}$ & $0.51(0.28-0.92)$ & 0.026 \\
\hline Motivation to quit smoking & $1.74(1.09-2.77)$ & 0.021 \\
\hline
\end{tabular}

Cox and Snell approximation for $R^{2}=0.33$, Nagelkerke approximation for $R^{2}=0.46$.
Table 5. Independent associations between predictor variables with actual uptake of genetic testing for lung cancer risk in multivariate logistic regression analysis

\begin{tabular}{|c|c|c|}
\hline \multirow[t]{2}{*}{ Variable } & \multicolumn{2}{|l|}{ Actual uptake } \\
\hline & $\exp b(95 \% \mathrm{CI})$ & $\mathrm{p}$ value \\
\hline Age & $1.02(0.98-1.07)$ & 0.32 \\
\hline Daily access to the Internet & $3.82(1.29-11.36)$ & 0.017 \\
\hline $\begin{array}{l}\text { Prior awareness of genetic tests } \\
\text { for cancer risks } \\
\text { Motivation to quit smoking }\end{array}$ & $\begin{array}{l}2.51(1.05-6.01) \\
1.52(1.08-2.15)\end{array}$ & $\begin{array}{l}0.041 \\
0.018\end{array}$ \\
\hline
\end{tabular}

Cox and Snell approximation for $R^{2}=0.15$, Nagelkerke approximation for $R^{2}=0.21$.

Table 4. Associations between personal characteristics and uptake of genetic testing for lung cancer risk in bivariate analyses $(\mathrm{n}=116)$

\begin{tabular}{|c|c|c|c|}
\hline \multirow[t]{2}{*}{ Variable } & \multicolumn{2}{|l|}{ Uptake } & \multirow[t]{2}{*}{ Significance } \\
\hline & $\begin{array}{l}\text { did not take } \\
\text { genetic test }\end{array}$ & took genetic test & \\
\hline \multicolumn{4}{|l|}{ Socio-demographics } \\
\hline \multicolumn{4}{|l|}{ Gender } \\
\hline Male & $35(65 \%)$ & $19(35 \%)$ & \multirow{2}{*}{$\chi^{2}=0.32, p=0.57$} \\
\hline Female & $37(60 \%)$ & $25(40 \%)$ & \\
\hline \multicolumn{4}{|l|}{ Age, years } \\
\hline $20-33$ & $30(73 \%)$ & $11(27 \%)$ & \multirow{3}{*}{$\chi^{2}=6.67, p=0.036$} \\
\hline $34-45$ & $18(46 \%)$ & $21(54 \%)$ & \\
\hline $46-54$ & $24(67 \%)$ & $12(33 \%)$ & \\
\hline \multicolumn{4}{|l|}{ Education } \\
\hline High school or less & $33(67 \%)$ & $16(33 \%)$ & \multirow{3}{*}{$\chi^{2}=1.20, p=0.55$} \\
\hline Some college & $23(56 \%)$ & $18(44 \%)$ & \\
\hline College graduate & $15(62 \%)$ & $10(39 \%)$ & \\
\hline \multicolumn{4}{|l|}{ Employment } \\
\hline Unemployed/part-time employed & $21(66 \%)$ & $11(34 \%)$ & \multirow{2}{*}{$\chi^{2}=0.24, p=0.63$} \\
\hline Full-time employed & $51(61 \%)$ & $33(39 \%)$ & \\
\hline \multicolumn{4}{|l|}{ Frequency of Internet access } \\
\hline Less than daily access & $25(81 \%)$ & $6(19 \%)$ & \multirow{2}{*}{$\chi^{2}=6.20, p=0.013$} \\
\hline Daily access & $47(55 \%)$ & $38(45 \%)$ & \\
\hline \multicolumn{4}{|l|}{ Awareness and cognitions } \\
\hline \multicolumn{4}{|l|}{ Prior awareness of genetic tests for cancer risk } \\
\hline Not aware & $42(71 \%)$ & $17(29 \%)$ & \multirow{2}{*}{$\chi^{2}=4.24, p=0.039$} \\
\hline Aware & $30(53 \%)$ & $27(47 \%)$ & \\
\hline Perceived risk of lung cancer, mean (SD) & $5.25(1.16)$ & $5.52(0.98)$ & $\mathrm{F}=1.70, \mathrm{p}=0.20$ \\
\hline Worry about lung cancer, mean (SD) & $3.51(1.20)$ & $3.91(1.20)$ & $\mathrm{F}=2.97, \mathrm{p}=0.087$ \\
\hline Positive attitudes towards genetic testing, mean (SD) & $4.29(0.73)$ & $4.52(0.73)$ & $\mathrm{F}=0.75, \mathrm{p}=0.39$ \\
\hline Negative attitudes towards genetic testing, mean (SD) & $1.99(0.85)$ & $1.94(0.81)$ & $\mathrm{F}=0.08, \mathrm{p}=0.78$ \\
\hline \multicolumn{4}{|l|}{ Smoking characteristics } \\
\hline Motivation to quit smoking, mean (SD) & $5.72(1.58)$ & $6.34(1.18)$ & $\mathrm{F}=5.04, \mathrm{p}=0.027$ \\
\hline Number of cigarettes per day, mean (SD) & $17.17(8.99)$ & $16.25(7.19)$ & $\mathrm{F}=0.33, \mathrm{p}=0.57$ \\
\hline Minutes until first cigarette, mean (SD) & $48.39(73.03)$ & $52.86(92.33)$ & $\mathrm{F}=0.08, \mathrm{p}=0.77$ \\
\hline
\end{tabular}


With the exception of motivation to quit smoking, the same factors that predicted interest in genetic testing did not predict actual uptake of genetic testing: attitudes towards genetic testing predicted interest but not uptake, whilst daily Internet access and prior awareness of genetic tests for cancer risk predicted uptake but not interest. Thus, our second hypothesis was largely not supported.

Rather than reflecting anticipated uptake $[26,27]$, our results suggest that interest in genetic testing for lung cancer in the abstract reflects generally positive attitudes towards and general acceptance of this emerging technology. Positive attitudes towards genetic testing for lung cancer risk were strongly associated with hypothetical interest in genetic testing but were not good predictors of the choices individuals made when offered such testing.

Generally, the findings suggest that correlates of interest in genetic testing may not provide useful information regarding the types of people that might ultimately be expected to take genetic tests. However, amongst people who had said they 'definitely would' take the genetic test if it were offered, concordance between this intention and their subsequent behavior was significantly higher amongst those with daily Internet access. The fact that the genetic test was actually offered online was a practical barrier that people could not factor into weighing initial interest, since there was no mention of the Internet in the hypothetical vignette. These findings therefore support a previous proposition that the more specific vignettes can be made, the more likely they are to accurately approximate real genetic testing situations [7]. Future studies that assess interest in genetic testing using vignettes should include a description of how the genetic test and test result are delivered, e.g., in person, over the phone, or via the Internet. Additionally, as previously suggested [7], response categories for interest measures which are not dichotomous but rather include multiple response options (e.g., 5-point Likert scales rather than yes/no responses) allow the distinction of those who respond that they are 'definitely' interested rather than only 'possibly' or 'probably' interested which, as our results indicate, more accurately identifies individuals who actually take genetic tests.

One consideration for future research is the amount and content of information that is optimal to give to participants and consumers to support their decision-making about, and interpretation of, genetic tests for susceptibility to common conditions. In this study, participants were given a lot of information to view and read online before deciding whether or not to take the genetic test. Whilst it is important that people are provided with sufficient information to make informed decisions, it is possible that this extensive information may have been offputting. Further research is needed to rigorously evaluate and refine genetics information materials given to individuals participating in genetic testing studies as well as to the general public.

Additionally, all smokers were offered genetic susceptibility testing at the time of a family member's diagnosis of cancer. This was done because it provided a possible teachable moment, when the salience of smoking risks might be high, with the expectation that it could further motivate relatives who smoke to engage more deeply with the information provided [15]. It is possible, however, that these circumstances prompted relatives to respond more favorably in the hypothetical to genetic testing, thus inflating the intention-behavior disconnect. Consideration of context and how it might influence the intention-behavior gap in future research will be important.

In conclusion, we have demonstrated an intention-behavior gap [4] with regard to uptake of genetic testing and identified that motivation to quit smoking appears to be a consistent motivating force for smokers both expressing interest in, and subsequently actually taking, a genetic test for a smoking-related disease. In order to prepare for the rapidly advancing availability of genetic testing, public health research is needed that employs a variety of methodologies, including vignettes and, when appropriate, actual genetic testing and test result feedback. This report contributes to our understanding of the tradeoffs of the 2 approaches.
References

Public Health Genomics 2010;13:116-124
Collins FS: Shattuck lecture - medical and societal consequences of the Human Genome Project. N Engl J Med 1999;341:28-37.

2 Feero WG, Guttmacher AE, Collins FS: The genome gets personal-almost. JAMA 2008; 299:1351-1352.

-3 Scheuner MT, Sieverding P, Shekelle PG: Delivery of genomic medicine for common chronic adult diseases: a systematic review. JAMA 2008;299:1320-1334.

4 Sheeran P: Intention-behavior relations: A conceptual and empirical review, in Stroebe W, Hewstone M (eds): European Review of Social Psychology, vol 12. Chichester, John Wiley \& Sons, 2002, pp 1-36.

5 Ropka ME, Wenzel J, Phillips EK, Siadaty M, Philbrick JT: Uptake rates for breast cancer genetic testing: a systematic review. Cancer Epidemiol Biomarkers Prev 2006; 15:840855. 
-6 Lerman C, Biesecker B, Benkendorf JL, Kerner J, Gomez-Caminero A, Hughes C, Reed MM: Controlled trial of pretest education approaches to enhance informed decision-making for BRCA1 gene testing. J Natl Cancer Inst 1997;89:148-157.

7 Persky S, Kaphingst KA, Condit CM, McBride CM: Assessing hypothetical scenario methodology in genetic susceptibility testing analog studies: a quantitative review. Genet Med 2007;9:727-738.

$\checkmark 8$ Westmaas JL, Woicik PB: Dispositional motivations and genetic risk feedback. Addict Behav 2005;30:1524-1534.

9 Lerman C, Croyle RT, Tercyak KP, Hamann $\mathrm{H}$ : Genetic testing: psychological aspects and implications. J Consult Clin Psychol 2002;70:784-797.

10 O`Neill SC, White DB, Sanderson SC, Lipkus IM, Bepler G, Bastian LA, McBride CM: The feasibility of online genetic testing for lung cancer susceptibility: uptake of a web-based protocol and decision outcomes. Genet Med 2008;10:121-130.

11 Petty RE, Cacioppo JT: The elaboration likelihood model of persuasion, in Berkowitz L (ed): Advances in Experimental Social Psychology. New York, Academic Press, 1986, pp 123-205.

12 Rogers RW: Cognitive and physiological processes in fear appeals and attitude change: a revised theory of protection motivation, in Cacioppo JT, Petty RE (eds): Social Psychophysiology: A Sourcebook. New York, Guilford Press, 1983, pp 153-176.
3 Ruiter RA, Kok G, Verplanken B, Brug J: Evoked fear and effects of appeals on attitudes to performing breast self-examination: an information-processing perspective. Health Educ Res 2001;16:307-319.

14 Witte K, Allen M: A meta-analysis of fear appeals: implications for effective public health campaigns. Health Educ Behav 2000;27: 591-615.

15 McBride CM, Emmons KM, Lipkus IM: Understanding the potential of teachable moments: the case of smoking cessation. Health Educ Res 2003;18:156-170.

16 Bratt O, Kristoffersson U, Lundgren R, Olsson $\mathrm{H}$ : Sons of men with prostate cancer: their attitudes regarding possible inheritance of prostate cancer, screening, and genetic testing. Urology 1997;50:360-365.

17 Bratt O, Damber JE, Emanuelsson M, Kristoffersson U, Lundgren R, Olsson H, Grönberg $\mathrm{H}$ : Risk perception, screening practice and interest in genetic testing among unaffected men in families with hereditary prostate cancer. Eur J Cancer 2000;36:235-241.

18 Cormier L, Valéri A, Azzouzi R, Fournier G, Cussenot O, Berthon P, Guillemin F, Mangin $P$ : Worry and attitude of men in at-risk families for prostate cancer about genetic susceptibility and genetic testing. Prostate 2002; 51:276-285.

19 Cowan R, Meiser B, Giles GG, Lindeman GJ, Gaff CL: The beliefs and reported and intended behaviors of unaffected men in response to their family history of prostate cancer. Genet Med 2008;10:430-438.

20 Diefenbach MA, Schnoll RA, Miller SM, Brower L: Genetic testing for prostate cancer. Willingness and predictors of interest. Cancer Pract 2000;8:82-86.
21 Doukas DJ, Li Y: Men's values-based factors on prostate cancer risk genetic testing: a telephone survey. BMC Med Genet 2004;5:28.

22 Miesfeldt S, Jones SM, Cohn W, Lippert M, Haden K, Turner BL, Martin-Fries T, Clark SM: Men's attitudes regarding genetic testing for hereditary prostate cancer risk. Urology 2000;55:46-50.

23 Sanderson SC, Wardle J, Jarvis MJ, Humphries SE: Public interest in genetic testing for susceptibility to heart disease and cancer: a population-based survey in the UK. Prev Med 2004;39:458-464.

24 Sanderson SC, Wardle J: Associations between anticipated reactions to genetic test results and interest in genetic testing: will self-selection reduce the potential for harm? Genet Test 2008;12:59-66.

25 Sanderson SC, Wardle J: Will genetic testing for complex diseases increase motivation to quit smoking? Anticipated reactions in a survey of smokers. Health Educ Behav 2005; 32:640-653.

26 Kasparian NA, Meiser B, Butow PN, Soames Job RF, Mann GJ: Anticipated uptake of genetic testing for familial melanoma in an Australian sample: an exploratory study. Psychooncology 2007;16:69-78.

-27 Struewing JP, Lerman C, Kase RG, Giambarresi TR, Tucker MA: Anticipated uptake and impact of genetic testing in hereditary breast and ovarian cancer families. Cancer Epidemiol Biomarkers Prev 1995;4:169-173. 